\title{
Clathrin-Independent Trafficking of AMPA Receptors
}

\author{
Oleg 0. Glebov, ${ }^{1,3}$ Cezar M. Tigaret, ${ }^{2}$ Jack R. Mellor, ${ }^{2}$ and Jeremy M. Henley ${ }^{1}$ \\ Schools of ${ }^{1}$ Biochemistry and ${ }^{2}$ Physiology and Pharmacology, Medical Research Council Centre for Synaptic Plasticity, University of Bristol, Bristol BS8 \\ 1TD, United Kingdom, and ${ }^{3}$ Wolfson Centre for Age-Related Diseases, King's College London, London SE1 1UL, United Kingdom
}

\begin{abstract}
Membrane trafficking of AMPA receptors (AMPARs) is critical for neuronal function and plasticity. Although rapid forms of AMPAR internalization during long-term depression (LTD) require clathrin and dynamin, the mechanisms governing constitutive AMPAR turnover and internalization of AMPARs during slow homeostatic forms of synaptic plasticity remain unexplored. Here, we show that, in contrast to LTD, constitutive AMPAR internalization and homeostatic AMPAR downscaling in rat neurons do not require dynamin or clathrin function. Instead, constitutive AMPAR trafficking is blocked by a Racl inhibitor and is regulated by a dynamic nonstructural pool of F-actin. Our findings reveal a novel role for neuronal clathrin-independent endocytosis controlled by actin dynamics and suggest that the interplay between different modes of receptor endocytosis provides for segregation between distinct modes of neuronal plasticity.
\end{abstract}

Key words: AMPA receptors; endocytosis; membrane trafficking; synaptic plasticity

\section{Introduction}

AMPA-type glutamate receptors (AMPARs) mediate most fast excitatory neurotransmission in the CNS, and their trafficking underpins synaptic function and dysfunction. AMPARs undergo continuous basal trafficking to and from synapses through constitutive exocytosis/endocytosis, and two distinct forms of synaptic plasticity, long-term depression (LTD) and homeostatic downscaling, rely on AMPAR internalization (Henley et al., 2011). Of these three processes, much is known about rapid removal of synaptic AMPARs during LTD, which requires clathrin-mediated endocytosis (CME) and a GTPase dynamin (Anggono and Huganir, 2012). In contrast, endocytic pathways involved in constitutive AMPAR trafficking and homeostatic downscaling remain poorly understood.

Mammalian cells possess a diverse array of noncanonical endocytic pathways that do not require dynamin and/or clathrin (Doherty and McMahon, 2009). In neurons, clathrin-independent endocytosis (CIE) is implicated in several modes of presynaptic vesicle retrieval (Jockusch et al., 2005; Xu et al., 2008; Chung et al., 2010)

Received Aug. 26, 2014; revised Nov. 6, 2014; accepted Nov. 8, 2014.

Author contributions: 0.0. G., J.R.M., and J.M.H. designed research; 0.0 .G. and C.M.T. performed research; 0.0. .G. C.M.T., and J.R.M. analyzed data; 0.0.G. and J.M.H. wrote the paper.

This work was supported by a London Law Trust Fellowship for Medical Research, a Beit Memorial Fellowship from the Wellcome Trust, and a Junior Research Fellowship from Trinity College Cambridge (0.0.G.), the Medical Research Council, European Research Council, and Biotechnology and Biological Sciences Research Council (J.M.H.), and the Wellcome Trust (C.M.T. and J.R.M.). We thank G. Banting, B. Nichols, J. O'Neill, N. Zenkin, D. Srivastava, P. Gordon-Weeks, and G. Lalli, as well as members of the Henley laboratory for advice on the manuscript and P. Tidball and P. Rubin for technical assistance.

This article is freely available online through the J Neurosci Author Open Choice option.

Correspondence should be addressed to either Oleg 0. Glebov or Jeremy M. Henley, School of Biochemistry,

Medical Research Council Centre for Synaptic Plasticity, Medical Sciences Building, University of Bristol, University Walk, Bristol BS8 1TD, UK. E-mail: oleg.glebov@kcl.ac.uk, anjmh@bristol.ac.uk.

DOI:10.1523/JNEUROSCI.3571-14.2015

Copyright $\odot 2015$ Glebov et al.

This is an Open Access article distributed under the terms of the Creative Commons Attribution License (http://creativecommons.org/licenses/by/3.0), which permits unrestricted use, distribution and reproduction in any medium provided that the original work is properly attributed. and growth cone dynamics (Bonanomi et al., 2008; Joset et al., 2010). To date, however, postsynaptic CIE has not been characterized.

To test the hypothesis that CIE may be involved in constitutive AMPAR trafficking and non-Hebbian plasticity, we used a number of approaches to perturb dynamin-mediated endocytosis and CME in neurons. We find that, in contrast to activity-dependent AMPAR internalization, neither constitutive AMPAR trafficking nor homeostatic downscaling require dynamin or clathrin function, although they do use the same intracellular trafficking compartments after internalization. Instead, constitutive AMPAR cycling is regulated by Racl and a nonstructural pool of F-actin that controls the rate of membrane turnover in the neuron. This novel mechanism highlights the diversity of membrane trafficking operating in the neuron and suggests that the distinct functional outcomes of different modes of AMPAR trafficking may be defined by differential endocytic sorting.

\section{Materials and Methods}

Reagents and DNA plasmids. Dynasore, Cy3-conjugated anti-myc 9E10 antibody, and HRP-conjugated secondary antibodies were from SigmaAldrich. Transferrin-, Cy3-, and Cy5-conjugated secondary antibodies were from Invitrogen. NSC23766 (6-N-[2-[5-(diethylamino)pentan-2ylamino]-6-methylpyrimidin-4-yl]-2-methylquinoline-4,6-diamine chloride) and dynamin inhibitory peptide (DIP) were from Tocris Bioscience. Dynole34-2 was a gift from P. Robinson (University of Sydney, New South Wales, Australia). Pitstop 2 was from Ascent Scientific. Rabbit anti-GluA1 antibody was from Merck. Mouse anti-GluA2 and anti-early endosome antigen 1 (EEA1) antibodies were from BD Biosciences. Anti-transferrin receptor (TfR) antibody was from Abcam. Dynamin 1 constructs were from P. De Camilli (Yale University, New Haven, CT), dynamin 3 constructs were from M. Ehlers (Pfizer, Cambridge, MA), Rab5-Q79L was from R. Lodge (Institut de recherches cliniques de Montréal, Montreal, QC, Canada), AP180Cmyc was from G. Banting (University of Bristol, UK), and shRNA against heavy chain of rat clathrin (CHC) was from L. Chen (Institute of Biophysics, Chinese Academy of Science, Beijing, China).

Cell culture and transfection. Dissociated hippocampal and cortical cultures were prepared as described previously (Rocca et al., 2008). Transfection of neuronal cultures was performed at 10-13 d in vitro 
A
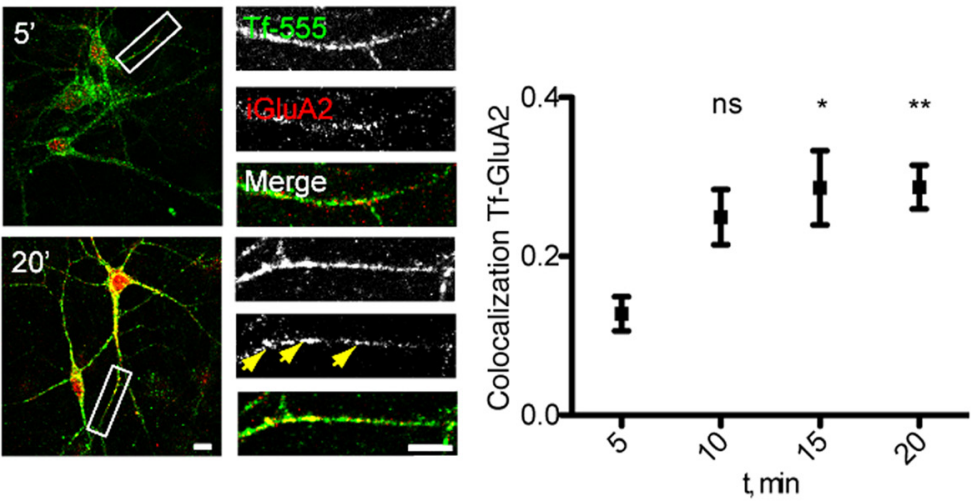

B
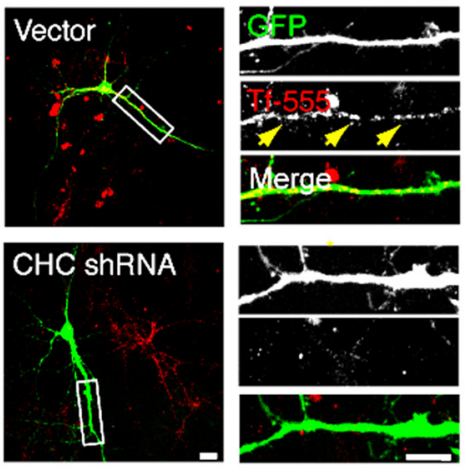

C

Tf-555

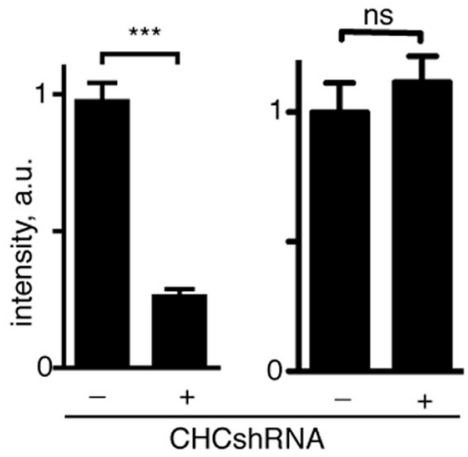

$\mathbf{E}$
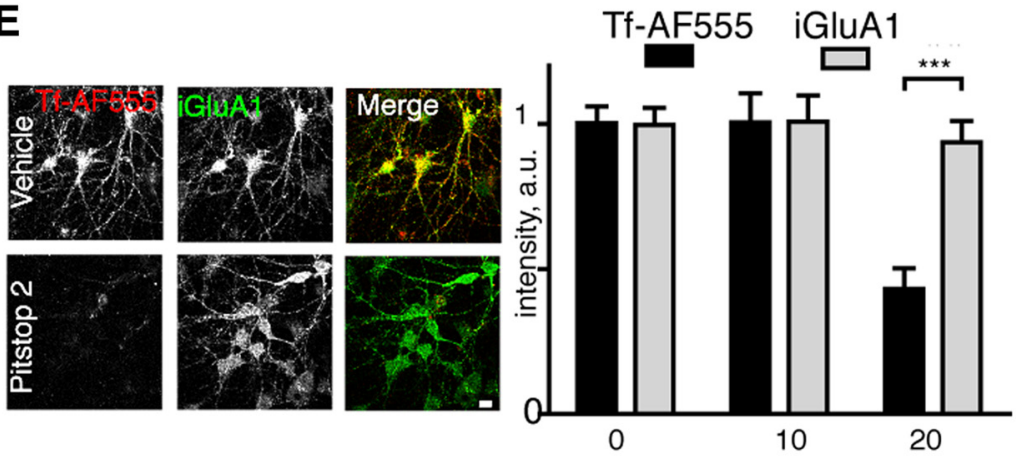

Pitstop, uM using Lipofectamine2000 (Invitrogen) according to the instructions of the manufacturer with minor modifications.

Biotinylation of cell surface protein. Live cortical neurons (15-21 d in vitro) were surface biotinylated on ice using the membraneimpermeant Sulfo-NHS-SS-Biotin according to the previously published protocol (Martin and Henley, 2004). Bands were quantified using NIH Image J software and normalized to the total receptor band intensity and internalization in the control sample.

Confocal imaging. Internalization assays for transferrin and anti-AMPAR subunit antibodies were performed as described previously (Rocca et al., 2008). Each experiment was performed using the same batch of coverslips and neurons cultured under identical conditions. Briefly, hippocampal neurons were live labeled for $20 \mathrm{~min}$ at $12-15^{\circ} \mathrm{C}$, washed, and allowed to internalize for $0-30 \mathrm{~min}$ before fixation. Surface label was revealed by overnight staining with an appropriate Cy3-conjugated secondary antibody, whereas internalized label was stained by an appropriate Cy5-conjugated secondary antibody after permeabilization. Images were acquired on LSM510 and LSM710 confocal microscopes (Zeiss) and analyzed using NIH ImageJ software. To minimize bias, quantification of internalization was performed by collecting random fields from various regions of the coverslip. The following formula for quantification of internalization was used:

$I=\left(I_{\mathrm{Cy} 5}-k \times I_{\mathrm{Cy} 3}\right) /\left(I_{\mathrm{Cy} 5}+(1-k) \times I_{\mathrm{Cy} 3}\right)$,

where $I_{\mathrm{Cy} 5}$ and $I_{\mathrm{Cy} 3}$ refer to intensities in Cy5 and $\mathrm{Cy} 3$ channels, respectively. Correction coefficient $k$ was calculated as follows:

$$
k=\left(I_{\mathrm{Cy} 5 t 0} / I_{\mathrm{Cy} 3 t 0}\right),
$$

where $I_{\mathrm{Cy} 5 t 0}$ and $I_{\mathrm{Cy} 3 t 0}$ refer to intensities in $\mathrm{Cy} 5$ and $\mathrm{Cy} 3$ at the 0 time point. To correct for the inherent variability in intensity of surface labeling between different cultures, resulting intensities were normalized so that the average intensity of the control sample was set to 1 .

The fraction of internalized AMPARs (iAMPARs) was quantified as loss of surface staining (sAMPARs) relative to the 0 time control. For colocalization analysis, surface remaining AMPARs were blocked with the

Figure 1. CIE of AMPARs. $A$, Neurons were incubated with Tf-555 and anti-GluA2 antibody for the indicated times, fixed, permeabilized, and stained for iGluA2. Arrows denote overlapping puncta visible at $20 \mathrm{~min}$, but not $5 \mathrm{~min}$, of internalization. $n=3$. $\boldsymbol{B}, \boldsymbol{C}$, Neurons were transfected with CHC shRNA or an empty GFP vector and live labeled with Tf-555 or anti-GluA1 for 30 min $4 \mathrm{~d}$ after transfection. Control, Empty GFP vector. CHC shRNA blocks uptake of Tf-555 but not iGluA1. Arrows denote puncta of internalized label. $n=4$. D, As above but with AP180Cmyc construct. Control, Untransfected cells. $n=$ 3. $\boldsymbol{E}$, Treatment with $20 \mu \mathrm{M}$ Pitstop 2 blocks Tf-555 but not iGluA1. $n=4$. Control, $0 \mu \mathrm{m}$ Pitstop2 (DMSO). Scale bars, $10 \mu \mathrm{m}$. 
A
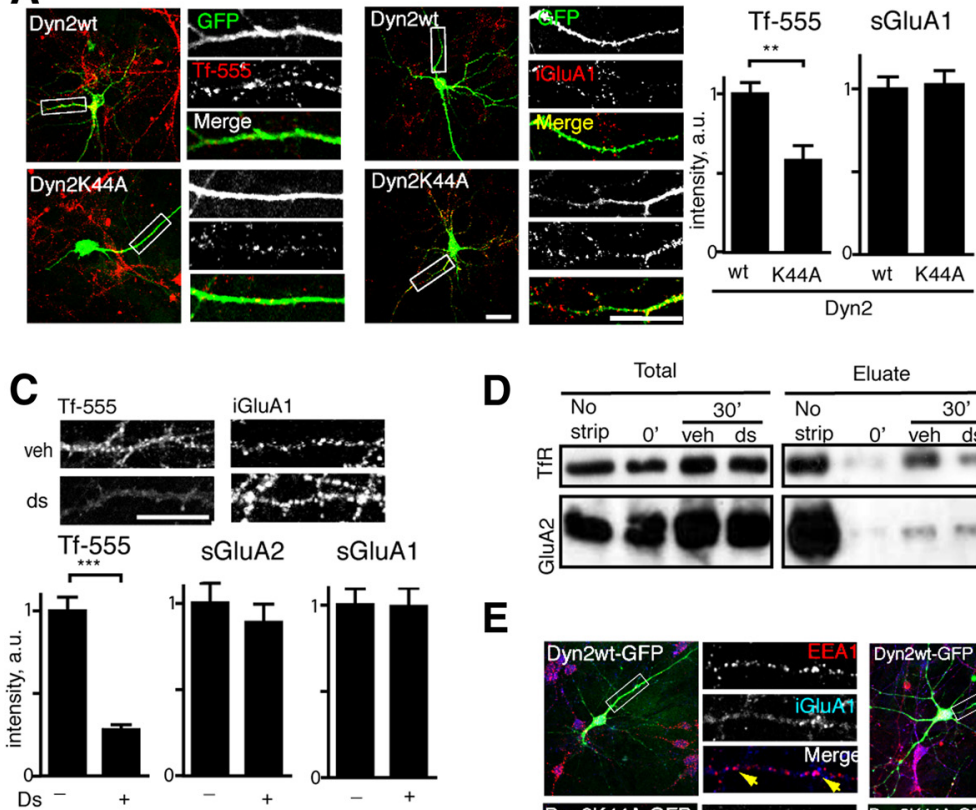

D

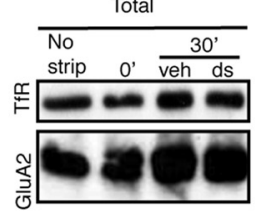

E

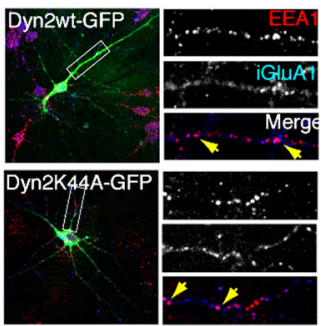

B

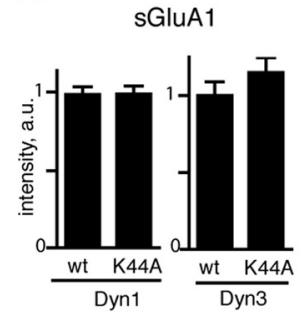

Figure 2. Dynamin-independent internalization of AMPARs. A, Neurons were transfected with Dyn2wt-GFP or Dyn2K44A-GFP and labeled with Tf-555 or anti-GluA1 2 d after transfection. Mutant Dyn2 reduces Tf- 555 but not iGluA1. Control, Dyn2wt-expressing cells. $n=4$. B, Overexpression of dynamin 1 and 3 mutants has no effect on iGluA1. Control, Dyn 1 wt and Dyn 3 wt-expressing cells, respectively. $n=3$ each. C, Neurons were pretreated with DMSO (veh) or $75 \mu$ m dynasore (ds) for 10 min and allowed to endocytose Tf-555, anti-GluA1, or anti-GluA2 for 30 min in the presence of dynasore. Ds blocks Tf-555 but not iGluA1 or iGluA2. Control, Vehicle-treated samples. $n=4$. D, Surface biotinylation-based assay for internalization in cortical neurons. Total, Total protein levels in neuronal lysate; Eluate, protein levels eluted from streptavidin-conjugated beads; No strip, nonstripped control; $0^{\prime}, 0$ time (no endocytosis) control. Ds blocks internalization of TfR but not of GluA2. Control, Vehicle-treated samples. $n=3$.E, Neurons expressing Dyn2wt-GFP or Dyn2K44A-GFP were live labeled with anti-GluA1, fixed, and stained for iGluA1 and either EEA1 or TfR. iGluA1 localizes to EEA1- and TfR-positive puncta (arrows) in both cells expressing wild-type and mutant dynamin. $\boldsymbol{F}$, Neurons expressing a dominant-negative Rab5079L-GFP construct accumulate AMPARs in GFP-positive enlarged endosomes (arrows). Scale bars, $20 \mu \mathrm{m}$.

excess of unconjugated secondary antibody overnight. The amount of colocalization was quantified using an ImageJ/Fiji Colocalization plugin (http://fiji.sc/Coloc_2).

Slice preparation. Acute hippocampal slices were prepared from anesthetized P13-P15 male Wistar rats. Brains were dissected in ice-cold artificial CSF (aCSF) equilibrated with $95 \% \mathrm{CO}_{2}$ and $5 \% \mathrm{O}_{2}$. Horizontal hippocampal slices (400-500 $\mu \mathrm{m}$ thick) were cut with a VT1200 vibratome (Leica) and incubated in aCSF at $36^{\circ} \mathrm{C}$ for $30 \mathrm{~min}$ and then at room temperature before use. The connections between CA 3 and CA1 were cut before transfer to the submerged recording chamber. The procedures were performed in accordance with the United Kingdom Home Office and University of Bristol guidelines.

Electrophysiology. Whole-cell recordings were made from CA1 pyramidal cells visualized with infrared differential interference contrast optics (Olympus BX-51 microscope) in a recording chamber perfused with aCSF $\left(35^{\circ} \mathrm{C}\right)$ containing $50 \mu \mathrm{m}$ picrotoxin. Patch electrodes $(4-5 \mathrm{M} \Omega$ ) were filled with intracellular solution (in mm: $117 \mathrm{CsMeSO}_{3}, 8 \mathrm{NaCl}, 10$ HEPES, 5 QX-314, 4 MgATP, 0.3 NaGTP, 0.5 EGTA, and 0.1 spermine), set to $\mathrm{pH} 7.4,280-285 \mathrm{mOsm}$. Cells were voltage clamped at $-70 \mathrm{mV}$, and the recorded currents were filtered at $4 \mathrm{kHz}$ and digitized at $10 \mathrm{kHz}$ using a CED Micro $1401 \mathrm{mk}$ II board and Signal 2 software (Cambridge Electronics Design). Cells with series resistance $>30 \mathrm{M} \Omega$ or showing $>20 \%$ change were discarded from subsequent analysis. Baseline synaptic responses were evoked at $0.2 \mathrm{~Hz}$ with a tungsten bipolar electrode (100 $\mathrm{k} \Omega, 119 \mu \mathrm{m}$ tip spacing; FHC) placed in the stratum radiatum. Consecutive EPSCs were averaged online every minute, and their amplitudes were normalized offline to the first minute of recording.

For synaptic plasticity experiments, EPSCs were recorded from two independent pathways. LTD was induced at 15-20 min after break-in by a pairing protocol $(1 \mathrm{~Hz} \times 300$ stimuli at $-40 \mathrm{mV})$ delivered to the test pathway, whereas the control pathway was paused. One-minute average EPSC amplitudes (see above) were normalized to the average value over 5 min before LTD induction.

Statistical analysis. Every experiment was performed at least in triplicate (see figure legends). Data were normalized to the control sample, and statistical analysis was performed using GraphPad Prism software (GraphPad Software). The D'Agostino-Pearson omnibus test was used to test for normality of distribution, and, depending on results, a twotailed $t$ test or Mann-Whitney nonparametric test was used. For ANOVA, one-way ANOVA with Dunn's post hoc test was used. Levels of statistical significance were as follows: ${ }^{*} p<0.05,{ }^{* *} p<0.01,{ }^{* *} p<$ 0.001. Error bars represent \pm SEM.

\section{Results}

Endogenous surface AMPARs in live cultured rat hippocampal neurons were labeled with antibodies recognizing extracellular epitopes of GluA1 and GluA2 subunits (Fig. 1A,B), and their internalization was monitored by immunofluorescence. In agreement with previous reports (Lin et al., 2000; Lu et al., 2007), we observed constitutive internalization of both GluA1 and GluA2, with $31.6 \pm 5.5$ and $36.5 \pm 4.9 \%$ of surface receptors, respectively, internalized after $20 \mathrm{~min}$. Although little overlap was observed between iAMPARs and fluorescent CME cargo transferrin Tf-Alexa Fluor 555 (Tf-555) at $5 \mathrm{~min}$, by $15 \mathrm{~min}$, there was significant colocalization between the two proteins (Fig. $1 A$ ). This observation raised the possibility that AMPARs and transferrin may internalize via distinct endocytic mechanisms but later converge within the same endosomal compartments. 
A

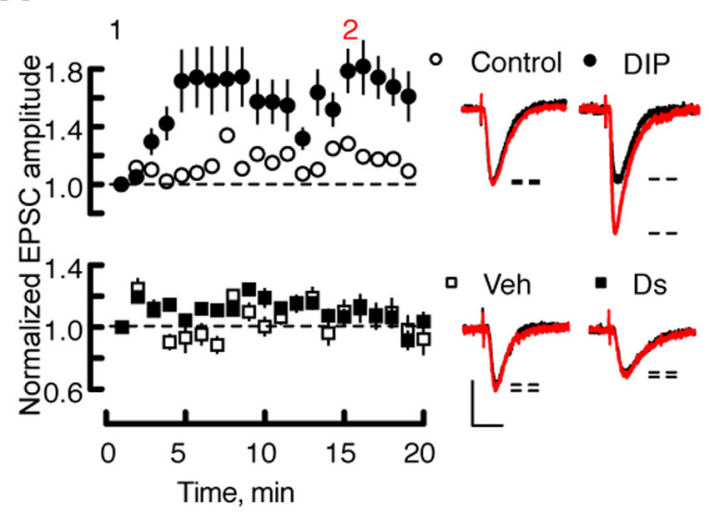

B

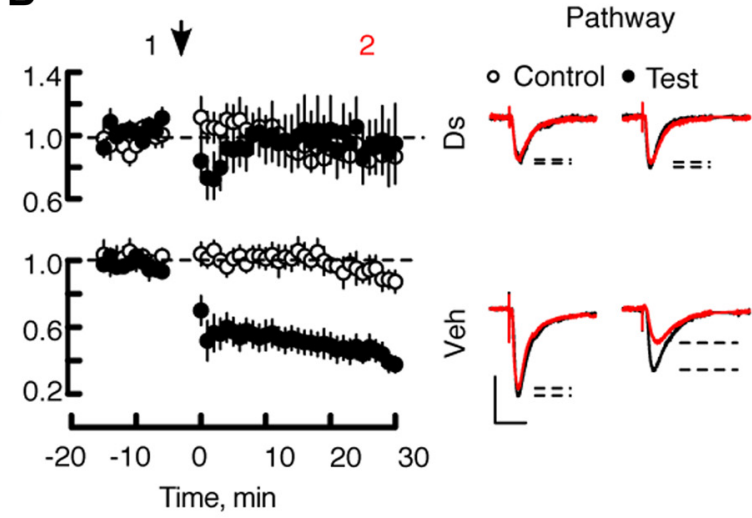

C

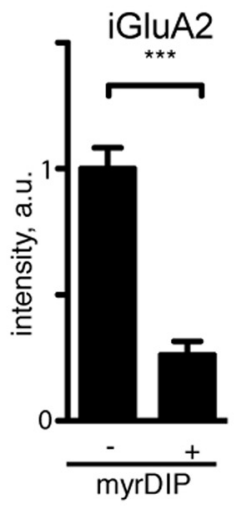

D
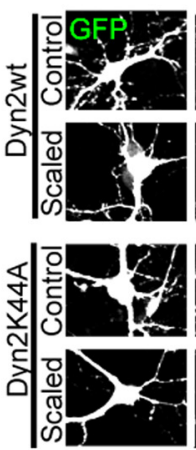
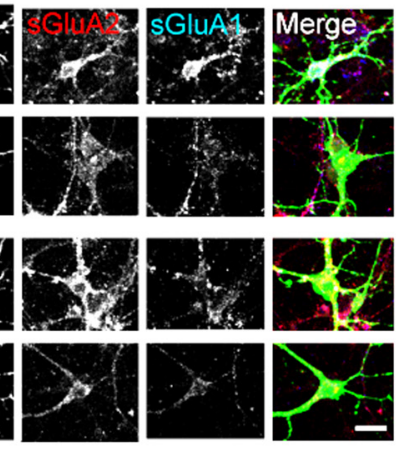

Figure 3. CME is required for NMDAR-LTD but not for basal synaptic transmission or synaptic downscaling. $A$, Treatment with dynasore does not affect basal excitatory synaptic transmission Time course of EPSC amplitude evoked at $0.2 \mathrm{~Hz}$ at Schaffer collateral-CA1 synapses after infusion of control $(n=6), 100 \mu \mathrm{m}$ dynasore (Ds; $n=8)$, vehicle (Veh, $0.1 \%$ DMSO; $n=6)$, or $50 \mu \mathrm{M}$ QVPSRPNRAP (DIP; $n=6$ ) by inclusion in the intracellular solution. $\boldsymbol{B}$, The pairing protocol effectively induces LTD with control intracellular solution (Control; $n=12$ ) but intracellular infusion of dynasore $(n=9)$ inhibits LTD in the test pathway. Right, Representative current traces from time points shown (1, black: 1 min before pairing; 2 , gray: 25 min after pairing). C, Application of 50 um myristoylated DIP (myrDIP) blocks AMPAR internalization in the live-labeling assay. Control, Vehicle-treated samples. $n=3$. D, Overexpression of the Dyn2-K44A construct does not affect homeostatic downscaling. Hippocampal neurons (12-14 din vitro) transfected with Dyn2wt-GFP or Dyn2K44A-GFP were treated with $15 \mathrm{~mm} \mathrm{KCl} \mathrm{and} 40 \mu \mathrm{m}$ bicuculline for $48 \mathrm{~h}$ ( $\mathrm{Scaled}$ ) and labeled to quantify sGluA1 and sGluA2. Control, Dyn2wt-expressing cells under control conditions. $n=3$. Scale bar, $20 \mu \mathrm{m}$.

To determine whether AMPAR internalization requires clathrin function, we knocked down the heavy chain of rat clathrin (CHC shRNA; He et al., 2008). Expression of CHC shRNA blocked internalization of transferrin but not AMPARs (Fig. $1 B, C)$. Similar results were obtained with overexpression of a dominant-negative variant of the clathrin adaptor protein AP180 (AP180C; Ford et al., 2001; Fig. 1D) and Pitstop $2(20 \mu \mathrm{M})$, a small molecule inhibitor of CME (von Kleist et al., 2011; Fig. 1E). Together, these data indicate that constitutive internalization of AMPARs does not require CME.

CME and several CIE pathways require the activity of the large GTPase dynamin to mediate scission of the budding endocytic vesicle from the plasma membrane (Doherty and McMahon, 2009). Therefore, we next tested whether dynamin activity was required for constitutive internalization of AMPARs. Although transferrin internalization was markedly reduced by a dominantnegative K44A dynamin 2 mutant (Dyn2-K44A; Damke et al., 1994), iAMPARs (Fig. 2A) and sAMPARs (Fig. 3D) were unaffected. Similar results were obtained for neuron-specific isoforms dynamin 1 and dynamin 3 (Fig. 2B). Consistent with these results, the dynamin GTPase inhibitor dynasore (Macia et al., 2006) blocked transferrin uptake but had no effect on iAMPARs (Fig.
$2 C)$, as did an alternative inhibitor of dynamin function, Dynole34-2 (Hill et al., 2009; data not shown). We also monitored the dynamin dependence of internalization using surface biotinylation in cultured cortical neurons. As expected, internalization of the TfR was inhibited by dynasore, whereas GluA2 was unaffected (Fig. 2D), confirming that dynamin is not required for constitutive AMPAR trafficking.

Depending on the context, cargoes endocytosed through CIE and CME may either follow separate intracellular trajectories or converge in endosomal compartments such as early and recycling endosomes (Hansen and Nichols, 2009). Given the time-dependent overlap between internalized transferrin and AMPARs (Fig. $1 A$ ), we investigated the post-internalization itinerary of AMPARs endocytosed via CIE. AMPARs internalized through CME during LTD are rapidly enriched in EEA1-positive early and TfR-positive recycling endosomes (Ehlers, 2000), and this was also the case for constitutively iAMPARs in both wildtype dynamin 2 (Dyn2wt) and Dyn2-K44A-expressing cells (Fig. $2 E)$. Additionally, iAMPARs colocalized with a GTPase-defective mutant of a small GTPase Rab5 (Fig. $2 F$ ), suggesting that constitutively iAMPARs traffic through Rab5-positive endosomes. Thus, AMPARs internalized via both CME and CIE traffic along 
A

B

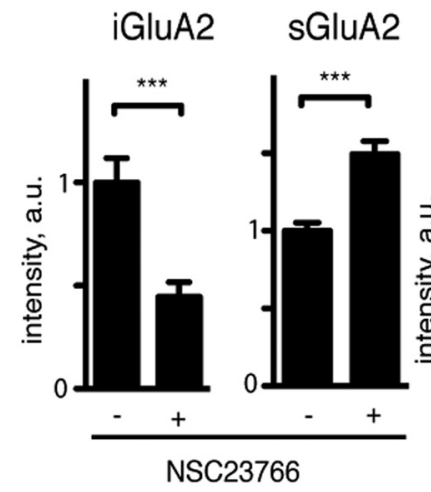

sGluA2

iGluA2

F-actin

C

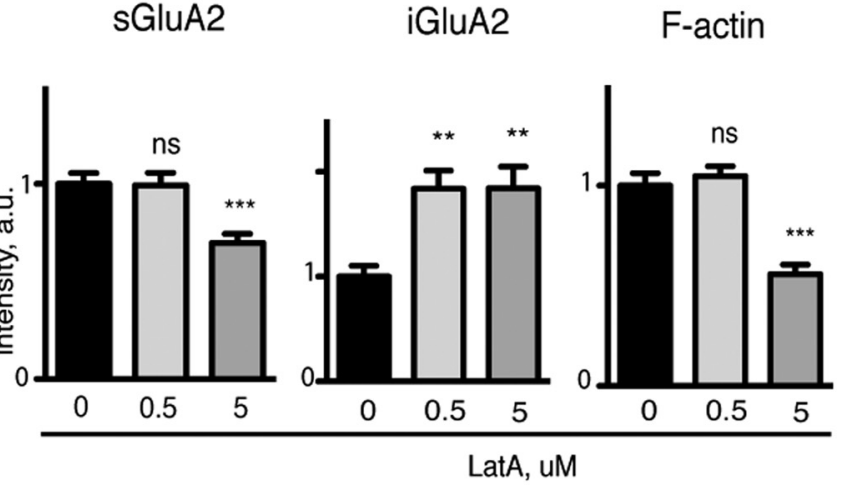

iGluA2

D

E

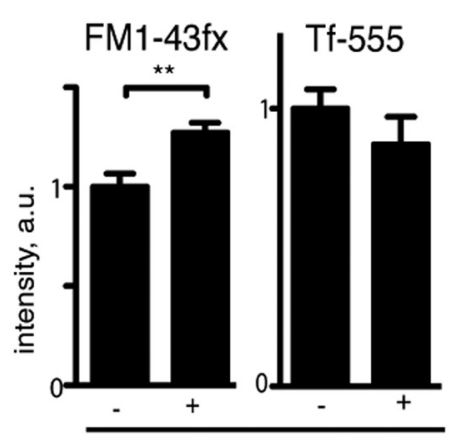

$0.5 \mathrm{uM}$ LatA
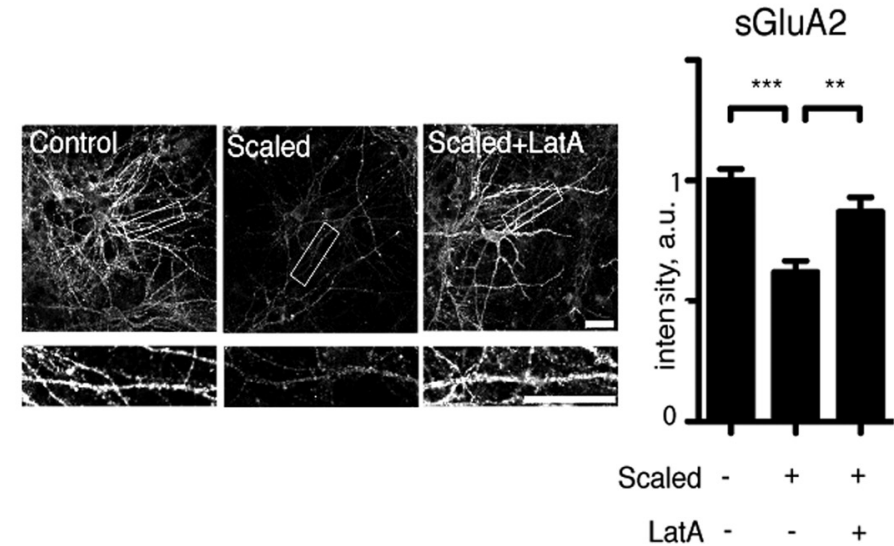

Figure 4. Nonstructural F-actin regulates AMPAR trafficking. $A$, Pharmacological inhibition of Rac1 inhibits AMPAR trafficking. Neurons were treated overnight with vehicle (DMSO) or $100 \mu \mathrm{M}$ NSC23766, and sGluA2 and iGluA2 levels were quantified. Control, DMSO. $n=4$. B, Treatment with $0.5 \mu \mathrm{m}$ LatA does not affect F-actin content but upregulates AMPAR trafficking. Neurons were treated overnight with vehicle (DMSO) or 5 or $0.5 \mu \mathrm{m}$ LatA, and sGluA2, iGluA2, and F-actin levels were quantified. Phalloidin-Alexa Fluor 568 was used to label F-actin. Control, DMSO $n=6$ (sGluA2 and iGluA2), $n=3$ (F-actin). C, Stabilization of F-actin by Jasplakinolide downregulates AMPAR trafficking. Neurons were treated overnight with vehicle (DMSO) or $1 \mu \mathrm{m}$ Jasplakinolide (Jas) and iGluA2 levels were quantified. Control, DMSO. $n=4$. $\boldsymbol{D}$, Treatment with $0.5 \mu \mathrm{m}$ LatA increases bulk membrane uptake but not CME. Neurons (14-21 $d$ in vitro) were treated as in $\boldsymbol{B}$ and then incubated with either FM1-43fx or Tf-555 for $30 \mathrm{~min}$. Control, DMSO $n=3 . E$, LatA at $0.5 \mu \mathrm{m}$ disrupts synaptic downscaling of GluA2. Hippocampal neurons were treated with $15 \mathrm{~mm} \mathrm{KCl}$ and $40 \mu \mathrm{M}$ bicuculline for $48 \mathrm{~h}$ (Scaled) in the presence of $0.5 \mu \mathrm{m}$ LatA, and sGluA2 levels were quantified. Control, DMSO-treated cells under control conditions. $n=3$. Scale bars, $20 \mu \mathrm{m}$.

the classical endocytic route, suggesting that convergence of these pathways at the level of early/recycling endosomes.

To assess the functional role of CIE in basal trafficking of synaptic AMPARs, we measured excitatory synaptic transmission in acute hippocampal slices. As a positive control, we used the DIP that contains the proline-rich domain from dynamin 1, which rapidly increases AMPAR currents (Lüscher et al., 1999) through blockade of AMPAR internalization (Fig. 3C). Although DIP effectively increased EPSC amplitude, dynasore did not alter EPSC amplitude (Fig. 3A). The discrepancy between the effects of DIP and dynasore suggests that the effect of DIP on basal AMPAR levels does not reflect the outcome of the functional inhibition of dynamin GTPase activity, given that the inhibitory effect of DIP is realized through its perturbation of the Src homology 3-domain interactions of an endocytic adaptor protein amphiphysin (Owen et al., 1998) rather than abrogation of dynamin GTPase activity, consistent with dynamin not being required for constitutive trafficking of AMPARs. In agreement with previous studies, dynasore abolished NMDAR-LTD (Man et al., 2000; Collingridge et al., 2010; Fig. 3B). In contrast, chronic enhancement of excitatory network activity using increased $\mathrm{K}^{+}$, and the $\mathrm{GABA}_{\mathrm{A}}$ receptor blocker bicuculline reduced sAMPARs in cells with or without dynamin (Fig. 3D). Together, these data indicate that inhibition of the GTPase dynamin function abolishes LTD but does not affect basal levels of synaptic AMPARs or their homeostatic downscaling.

To elucidate the molecular mechanism of CIE-AMPAR, we focused as a candidate on a small GTPase Racl that clusters AMPARs in developing dendrites (Wiens et al., 2005) and regulates dynamin-independent macropinocytosis at the growth cone (Joset et al., 2010). Because neurons overexpressing Racl mutants exhibited profound morphological aberrations, we instead chose to pharmacologically inhibit Racl activation by the drug NSC23766 (Gao et al., 2004), which did not noticeably affect the cell morphology. NSC23766 increased sAMPARs and decreased iAMPARs (Fig. 4A), indicating that Racl activation was required for constitutive AMPAR trafficking.

Given that Racl regulates membrane trafficking processes through control of actin polymerization, we tested the role of actin in AMPAR internalization. As reported previously (Zhou et al., 2001), treatment with $5 \mu \mathrm{M}$ Latrunculin A (LatA) decreased F-actin and sAMPARs but increased iAMPARs (Fig. 4B). Stabilization of F-actin by Jasplakinolide had the opposite effect (Fig. $4 C$ ), suggesting a bidirectional regulation of constitutive AMPAR trafficking by actin dynamics.

We next asked whether the effect of actin is mediated directly on AMPAR trafficking or indirectly via its structural role at the synapse. The reported existence of distinct dendritic F-actin pools with dif- 
ferent dynamics and sensitivities to LatA (Gu et al., 2010) prompted us to attempt to pharmacologically uncouple the structural and nonstructural functions of actin. LatA at $0.5 \mu \mathrm{M}$ had no effect on the overall levels of dendritic F-actin (Fig. $4 B$ ), suggesting that the structural pool of F-actin remained intact, whereas lack of effect on synaptic AMPARs (data not shown) indicated that limited depolymerization of F-actin did not affect AMPAR distribution, ruling out the homeostatic effect of enhanced neurotransmitter release. Strikingly, $0.5 \mu \mathrm{M}$ LatA increased iGluA2 to the same extent as $5 \mu \mathrm{M}$ (Fig. $4 B)$ and also increased the uptake of a membrane-binding dye FM1$43 \mathrm{fx}$ [fixable $N$-(3-triethylammoniumpropyl)-4-(4-(dibutylamino) styryl) pyridinium dibromide] but not of transferrin (Fig. 4D), suggesting that the observed increase of AMPAR cycling is likely attributable to the increase in the overall dendritic CIE. Furthermore, 0.5 $\mu \mathrm{M}$ LatA abolished the reduction of sAMPARs induced by bicuculline and $\mathrm{KCl}$ (Fig. 4E), indicating that this nonstructural pool of actin was required for homeostatic downscaling.

\section{Discussion}

To date, the majority of AMPAR endocytosis studies have been focused on LTD (Anggono and Huganir, 2012), and therefore, it has been commonly assumed that AMPARs traffic exclusively via CME. Here, we use a wide variety of acute and chronic loss-offunction approaches to show that basal internalization and homeostatic downscaling of AMPARs proceed normally in the absence of clathrin or dynamin function. Although individual pharmacological and genetic tools may in some cases exhibit offtarget effects (Dutta et al., 2012; Park et al., 2013; Willox et al., 2014) and compensatory upregulation (Damke et al., 1995), CIE of AMPARs is observed regardless of the methodology used. Although the full molecular details of the endocytic pathway remains to be established, our data reveal a surprising fundamental difference between the fast (LTD) and slow (constitutive cycling, homeostatic downscaling) modalities of neuronal receptor endocytosis. Therefore, it is tempting to speculate that differential commitment of the same cargo to distinct endocytic itineraries (Di Guglielmo et al., 2003) may provide a parsimonious mechanistic framework for explaining the subsequent fates of AMPAR molecules internalized during constitutive cycling, homeostatic downscaling, and LTD (Henley et al., 2011).

Loss of synaptic AMPARs and decreased synaptic transmission after actin depolymerization has been generally interpreted as an indirect consequence of the structural disruption of the spine and synapse (Zhou et al., 2001; Hotulainen and Hoogenraad, 2010). We show that a dynamic pool of F-actin limits endocytic AMPAR trafficking and total membrane uptake but has no obvious role in the maintenance of the structural integrity of the synapse. This trafficking pool of F-actin has distinct properties from the main dendritic F-actin, allowing for functional uncoupling between structural plasticity and membrane trafficking. These findings indicate that the structural role of actin at the synapse is realized independently from its role in the organization of local membrane trafficking and are in line with recent reports of multiple pools of actin coexisting at the synapse ( $\mathrm{Gu}$ et al., 2010). It remains to be determined which of the actin regulatory proteins resident at the synapse may define the distinct identities of these pools.

Dynamin-independent internalization of both major AMPAR subunits and the distinct cytoskeletal regulation of bulk membrane uptake from CME suggest that this pathway may potentially function as a nonselective recycling route for any cargo that fails to be sequestered into a adaptor-driven endocytic pathway, such as CME. Indeed, although our study has predominantly focused on AMPAR trafficking, evidence is accumulating that CIE may carry other cargo receptors in other synaptic contexts (Cinar and Barnes, 2001; Kumari et al., 2008; Borroni and Barrantes, 2011). This emerging diversity of synaptic receptor trafficking challenges the extant perception of CME as the predominant endocytic mechanism in neurons and raises new questions about the mechanisms and regulatory pathways that allow neurons to regulate their function.

\section{References}

Anggono V, Huganir RL (2012) Regulation of AMPA receptor trafficking and synaptic plasticity. Curr Opin Neurobiol 22:461-469. CrossRef Medline

Bonanomi D, Fornasiero EF, Valdez G, Halegoua S, Benfenati F, Menegon A, Valtorta F (2008) Identification of a developmentally regulated pathway of membrane retrieval in neuronal growth cones. J Cell Sci 121:37573769. CrossRef Medline

Borroni V, Barrantes FJ (2011) Cholesterol modulates the rate and mechanism of acetylcholine receptor internalization. J Biol Chem 286:1712217132. CrossRef Medline

Chung C, Barylko B, Leitz J, Liu X, Kavalali ET (2010) Acute dynamin inhibition dissects synaptic vesicle recycling pathways that drive spontaneous and evoked neurotransmission. J Neurosci 30:1363-1376. CrossRef Medline

Cinar H, Barnes EM Jr (2001) Clathrin-independent endocytosis of GABA A receptors in HEK 293 cells. Biochemistry 40:14030-14036. CrossRef Medline

Collingridge GL, Peineau S, Howland JG, Wang YT (2010) Long-term depression in the CNS. Nat Rev Neurosci 11:459-473. CrossRef Medline

Damke H, Baba T, Warnock DE, Schmid SL (1994) Induction of mutant dynamin specifically blocks endocytic coated vesicle formation. J Cell Biol 127:915-934. CrossRef Medline

Damke H, Baba T, van der Bliek AM, Schmid SL (1995) Clathrinindependent pinocytosis is induced in cells overexpressing a temperaturesensitive mutant of dynamin. J Cell Biol 131:69-80. CrossRef Medline

Di Guglielmo GM, Le Roy C, Goodfellow AF, Wrana JL (2003) Distinct endocytic pathways regulate TGF-beta receptor signalling and turnover. Nat Cell Biol 5:410-421. CrossRef Medline

Doherty GJ, McMahon HT (2009) Mechanisms of endocytosis. Annu Rev Biochem 78:857-902. CrossRef Medline

Dutta D, Williamson CD, Cole NB, Donaldson JG (2012) Pitstop 2 is a potent inhibitor of clathrin-independent endocytosis. PLoS One 7:e45799. CrossRef Medline

Ehlers MD (2000) Reinsertion or degradation of AMPA receptors determined by activity-dependent endocytic sorting. Neuron 28:511-525. CrossRef Medline

Ford MG, Pearse BM, Higgins MK, Vallis Y, Owen DJ, Gibson A, Hopkins CR, Evans PR, McMahon HT (2001) Simultaneous binding of PtdIns(4,5)P2 and clathrin by AP180 in the nucleation of clathrin lattices on membranes. Science 291:1051-1055. CrossRef Medline

Gao Y, Dickerson JB, Guo F, Zheng J, Zheng Y (2004) Rational design and characterization of a Rac GTPase-specific small molecule inhibitor. Proc Natl Acad Sci U S A 101:7618-7623. CrossRef Medline

Gu J, Lee CW, Fan Y, Komlos D, Tang X, Sun C, Yu K, Hartzell HC, Chen G, Bamburg JR, Zheng JQ (2010) ADF/cofilin-mediated actin dynamics regulate AMPA receptor trafficking during synaptic plasticity. Nat Neurosci 13:1208-1215. CrossRef Medline

Hansen CG, Nichols BJ (2009) Molecular mechanisms of clathrinindependent endocytosis. J Cell Sci 122:1713-1721. CrossRef Medline

He Z, Fan J, Kang L, Lu J, Xue Y, Xu P, Xu T, Chen L (2008) Ca2+ triggers a novel clathrin-independent but actin-dependent fast endocytosis in pancreatic beta cells. Traffic 9:910-923. CrossRef Medline

Henley JM, Barker EA, Glebov OO (2011) Routes, destinations and delays: recent advances in AMPA receptor trafficking. Trends Neurosci 34:258268. CrossRef Medline

Hill TA, Gordon CP, McGeachie AB, Venn-Brown B, Odell LR, Chau N, Quan A, Mariana A, Sakoff JA, Chircop M, Robinson PJ, McCluskey A (2009) Inhibition of dynamin mediated endocytosis by the dynolessynthesis and functional activity of a family of indoles. J Med Chem 52: 3762-3773. CrossRef Medline 
Hotulainen P, Hoogenraad CC (2010) Actin in dendritic spines: connecting dynamics to function. J Cell Biol 189:619-629. CrossRef Medline

Jockusch WJ, Praefcke GJ, McMahon HT, Lagnado L (2005) Clathrindependent and clathrin-independent retrieval of synaptic vesicles in retinal bipolar cells. Neuron 46:869-878. CrossRef Medline

Joset A, Dodd DA, Halegoua S, Schwab ME (2010) Pincher-generated Nogo-A endosomes mediate growth cone collapse and retrograde signaling. J Cell Biol 188:271-285. CrossRef Medline

Kumari S, Borroni V, Chaudhry A, Chanda B, Massol R, Mayor S, Barrantes FJ (2008) Nicotinic acetylcholine receptor is internalized via a Racdependent, dynamin-independent endocytic pathway. J Cell Biol 181: 1179-1193. CrossRef Medline

Lin JW, Ju W, Foster K, Lee SH, Ahmadian G, Wyszynski M, Wang YT, Sheng M (2000) Distinct molecular mechanisms and divergent endocytotic pathways of AMPA receptor internalization. Nat Neurosci 3:1282-1290. CrossRef Medline

Lu J, Helton TD, Blanpied TA, Rácz B, Newpher TM, Weinberg RJ, Ehlers MD (2007) Postsynaptic positioning of endocytic zones and AMPA receptor cycling by physical coupling of dynamin-3 to Homer. Neuron 55:874-889. CrossRef Medline

Lüscher C, Xia H, Beattie EC, Carroll RC, von Zastrow M, Malenka RC, Nicoll RA (1999) Role of AMPA receptor cycling in synaptic transmission and plasticity. Neuron 24:649-658. CrossRef Medline

Macia E, Ehrlich M, Massol R, Boucrot E, Brunner C, Kirchhausen T (2006) Dynasore, a cell-permeable inhibitor of dynamin. Dev Cell 10:839-850. CrossRef Medline

Man HY, Lin JW, Ju WH, Ahmadian G, Liu L, Becker LE, Sheng M, Wang YT (2000) Regulation of AMPA receptor-mediated synaptic transmission by clathrin-dependent receptor internalization. Neuron 25:649-662. CrossRef Medline

Martin S, Henley JM (2004) Activity-dependent endocytic sorting of kai- nate receptors to recycling or degradation pathways. EMBO J 23:4749 4759. CrossRef Medline

Owen DJ, Wigge P, Vallis Y, Moore JD, Evans PR, McMahon HT (1998) Crystal structure of the amphiphysin-2 SH3 domain and its role in the prevention of dynamin ring formation. EMBO J 17:5273-5285. CrossRef Medline

Park RJ, Shen H, Liu L, Liu X, Ferguson SM, De Camilli P (2013) Dynamin triple knockout cells reveal off target effects of commonly used dynamin inhibitors. J Cell Sci 126:5305-5312. CrossRef Medline

Rocca DL, Martin S, Jenkins EL, Hanley JG (2008) Inhibition of Arp2/3mediated actin polymerization by PICK1 regulates neuronal morphology and AMPA receptor endocytosis. Nat Cell Biol 10:259-271. CrossRef Medline

von Kleist L, Stahlschmidt W, Bulut H, Gromova K, Puchkov D, Robertson MJ, MacGregor KA, Tomilin N, Pechstein A, Chau N, Chircop M, Sakoff J, von Kries JP, Saenger W, Kräusslich HG, Shupliakov O, Robinson PJ, McCluskey A, Haucke V (2011) Role of the clathrin terminal domain in regulating coated pit dynamics revealed by small molecule inhibition. Cell 146:471-484. CrossRef Medline

Wiens KM, Lin H, Liao D (2005) Rac1 induces the clustering of AMPA receptors during spinogenesis. J Neurosci 25:10627-10636. CrossRef Medline

Willox AK, Sahraoui YME, Royle SJ (2014) Non-specificity of Pitstop 2 in clathrin-mediated endocytosis. Biol Open 3:326-331. CrossRef Medline

Xu J, McNeil B, Wu W, Nees D, Bai L, Wu LG (2008) GTP-independent rapid and slow endocytosis at a central synapse. Nat Neurosci 11:45-53. CrossRef Medline

Zhou Q, Xiao M, Nicoll RA (2001) Contribution of cytoskeleton to the internalization of AMPA receptors. Proc Natl Acad Sci U S A 98:12611266. CrossRef Medline 